\title{
Anthanthrene Derivatives as Blue Emitting Materials for OLED Applications
}

\author{
Bipin K. Shah, * Douglas C. Neckers*
}

Center for Photochemical Sciences, Bowling Green State University, Bowling Green, Ohio 43403

Jianmin Shi, * Eric W. Forsythe, David Morton

U. S. Army Research Laboratory, AMSRD-SE-EO, 2800 Power Mill Road, Adelphi, Maryland 20783

bipin@bgnet.bgsu.edu; neckers@photo.bgsu.edu; jshi@arl.army.mil

\section{Supporting Information}

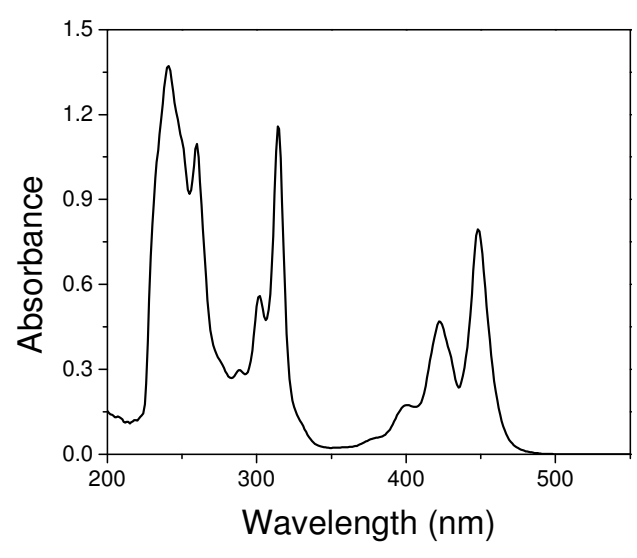

Figure S1. Absorption spectra of $\mathbf{3}$ recorded in $\mathrm{CH}_{2} \mathrm{Cl}_{2}$.

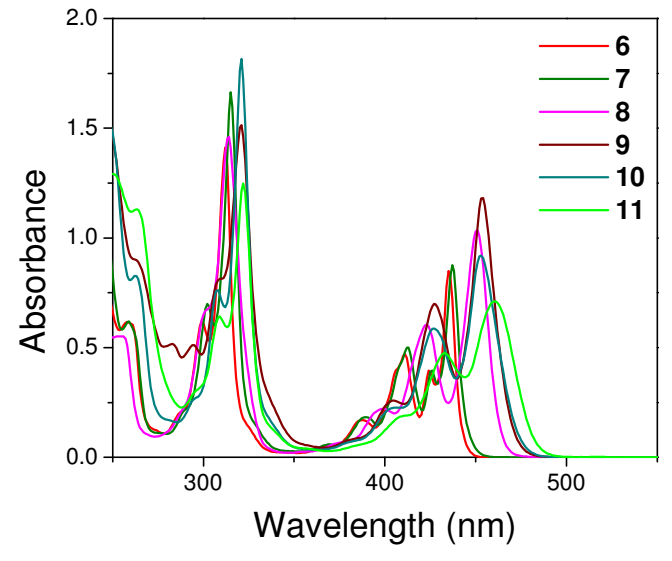

Figure S2. Absorption spectra of 6-11 recorded in $\mathrm{CH}_{2} \mathrm{Cl}_{2}$. 

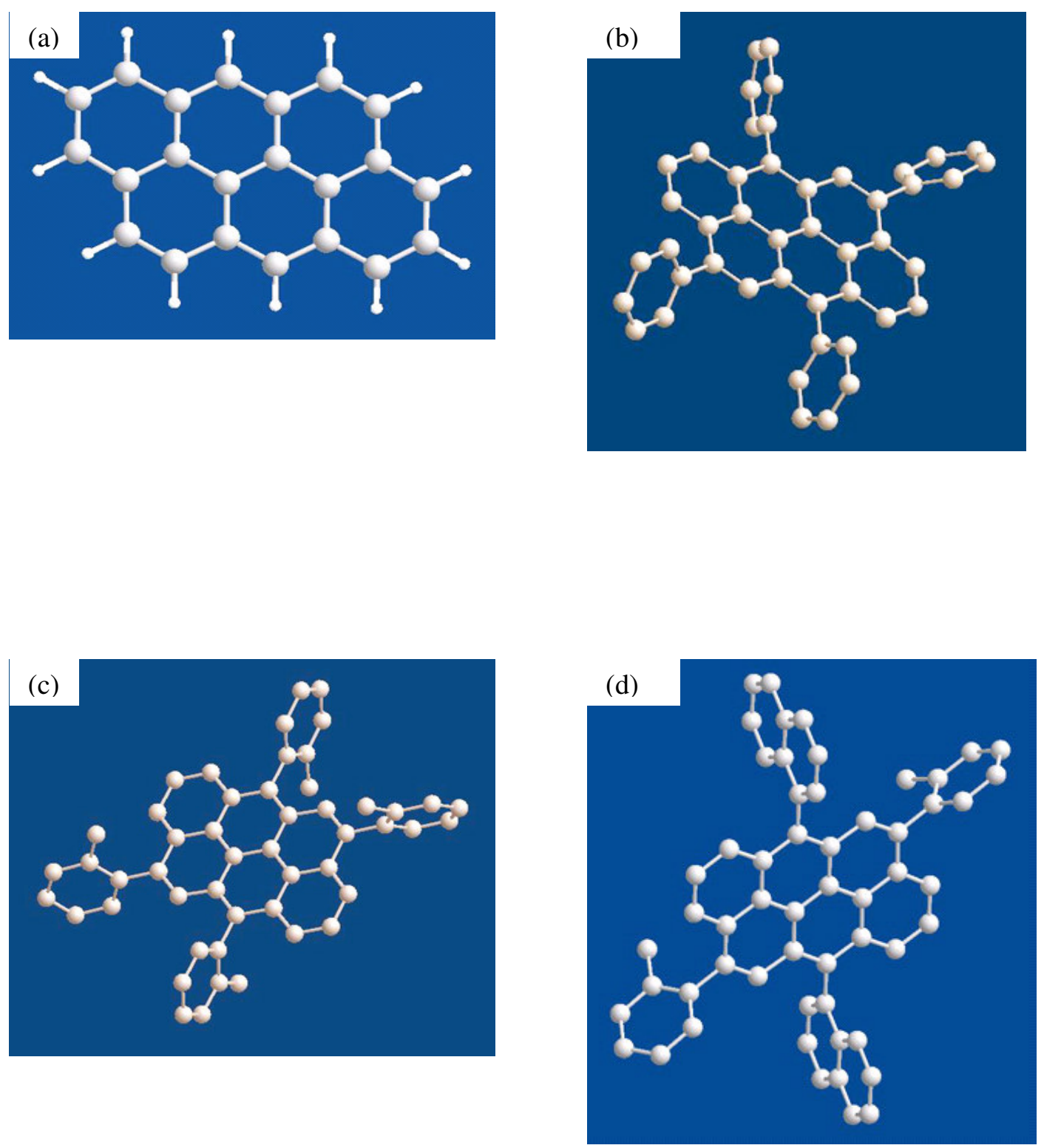

Figure S3. The geometry optimized structures of (a) 1, (b) 4, (c) 8, and (d) 9 by density functional theory method using B3LYP/6-31G* level of basis sets. Figures (a) and (b) are taken from ref. 5. 


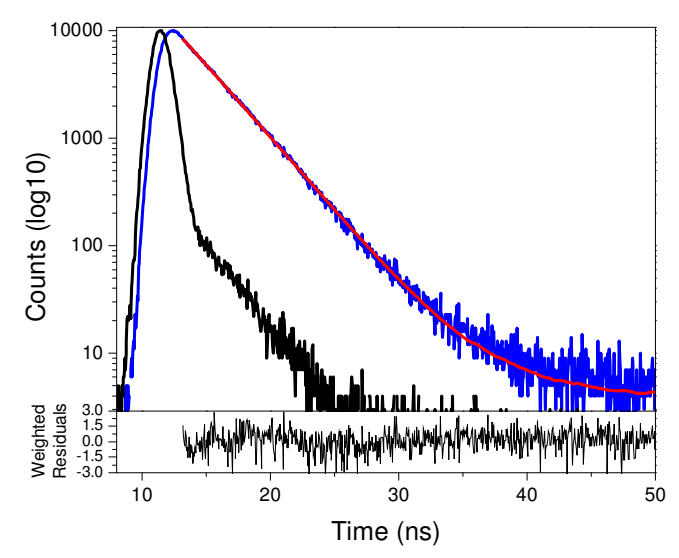

Figure S4. Decay of fluorescence of $\mathbf{1}$ monitored at $437 \mathrm{~nm}$ (solv.- $\left.\mathrm{CH}_{2} \mathrm{Cl}_{2}\right)\left(\chi^{2}\right.$ $=1.15)$. Ref. 5 .

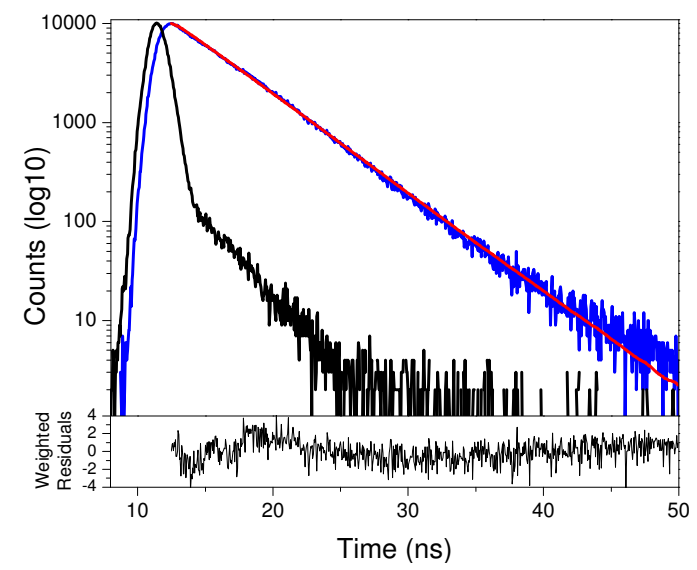

Figure S5. Decay of fluorescence of 2 monitored at $442 \mathrm{~nm}$ (solv.- $\left.\mathrm{CH}_{2} \mathrm{Cl}_{2}\right)\left(\chi^{2}\right.$ $=1.58)$.

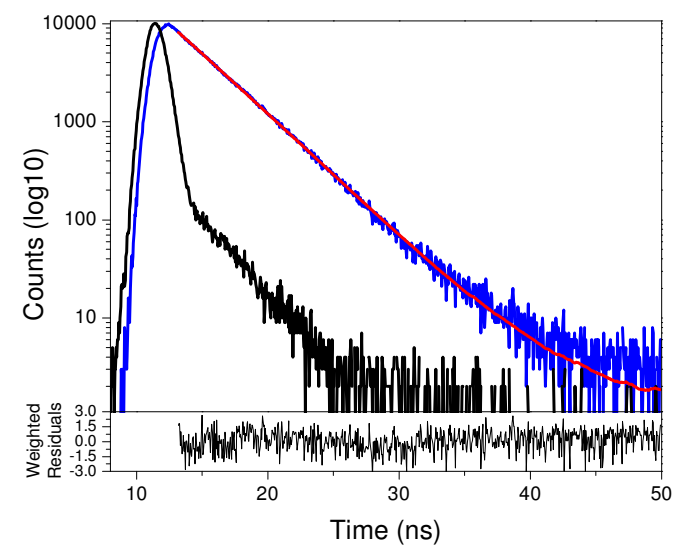

Figure S6. Decay of fluorescence of $\mathbf{3}$ monitored at $457 \mathrm{~nm}$ (solv.- $\left.\mathrm{CH}_{2} \mathrm{Cl}_{2}\right)\left(\chi^{2}\right.$ $=1.35)$.

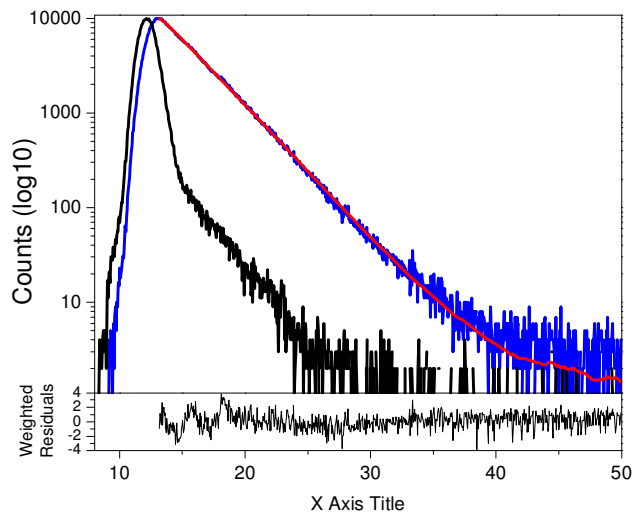

Figure S7. Decay of fluorescence of 4 monitored at $462 \mathrm{~nm}$ (solv.- $\left.\mathrm{CH}_{2} \mathrm{Cl}_{2}\right)\left(\chi^{2}\right.$ $=1.32$ ).

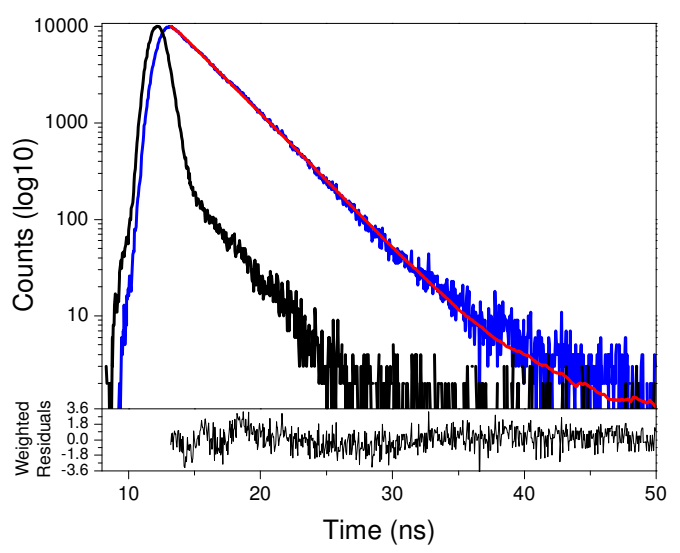

Figure S8. Decay of fluorescence of 5 monitored at $467 \mathrm{~nm}$ (solv.- $\left.\mathrm{CH}_{2} \mathrm{Cl}_{2}\right)\left(\chi^{2}\right.$ $=1.39$ ).

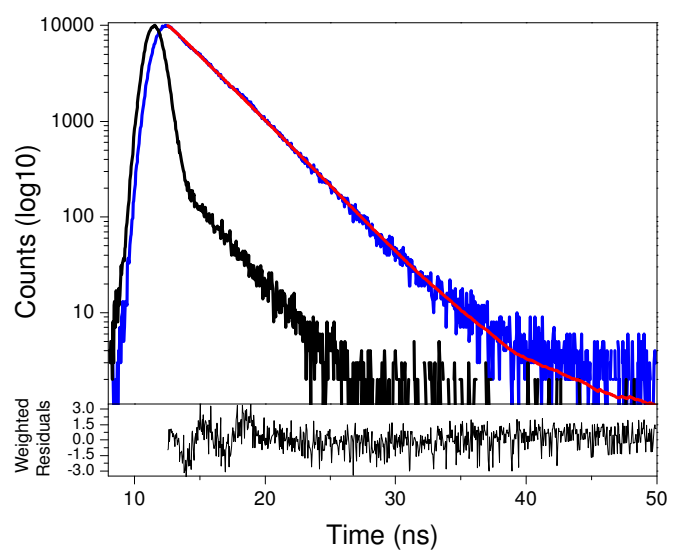

Figure S9. Decay of fluorescence of 6 monitored at $438 \mathrm{~nm}$ (solv.- $\left.\mathrm{CH}_{2} \mathrm{Cl}_{2}\right)\left(\chi^{2}\right.$ $=1.43$ ). 


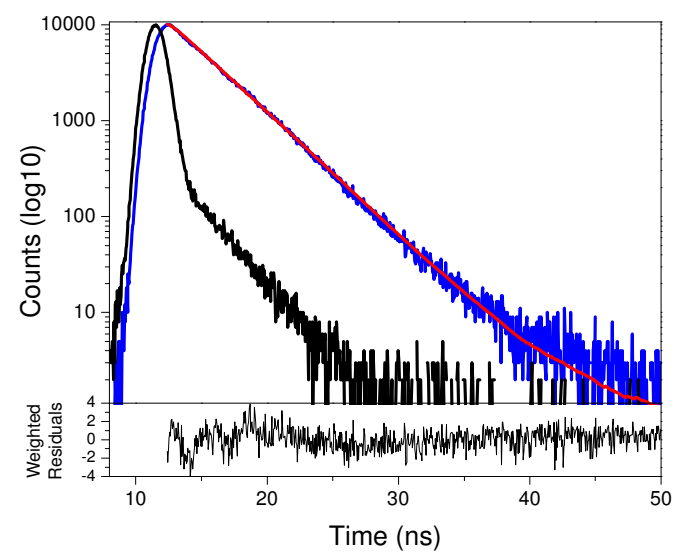

Figure S10. Decay of fluorescence of 7 monitored at $440 \mathrm{~nm}$ (solv.- $\left.\mathrm{CH}_{2} \mathrm{Cl}_{2}\right)\left(\chi^{2}\right.$ $=1.29$ ).

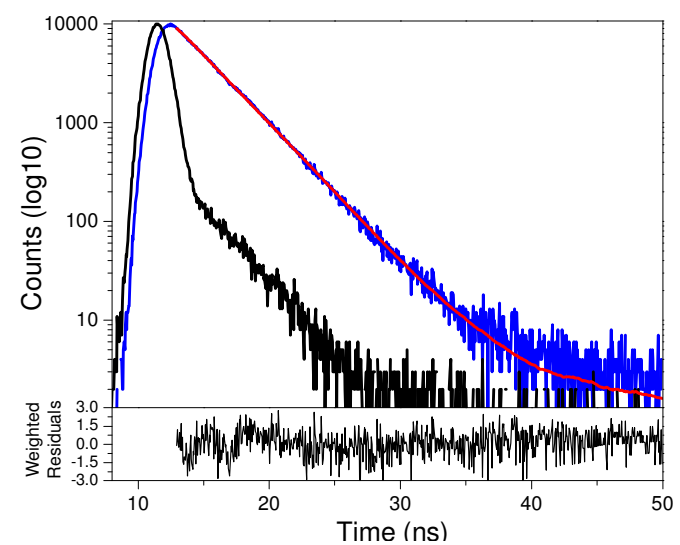

Figure S11. Decay of fluorescence of 8 monitored at $455 \mathrm{~nm}$ (solv.- $\left.\mathrm{CH}_{2} \mathrm{Cl}_{2}\right)\left(\chi^{2}\right.$ $=1.21$ ).

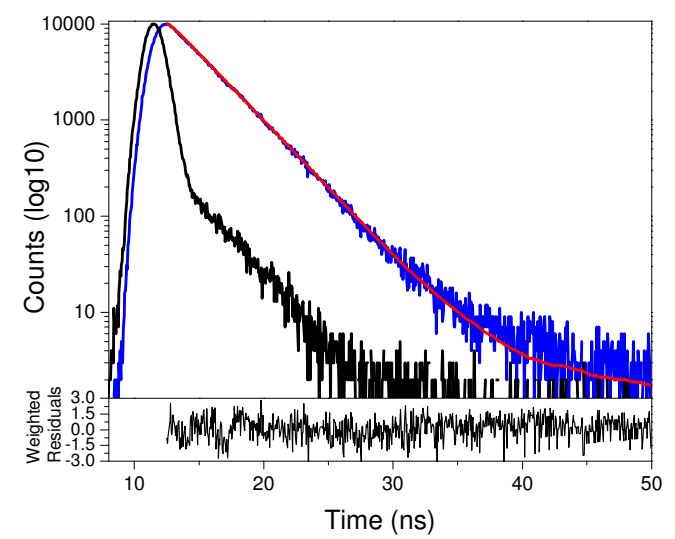

Figure S12. Decay of fluorescence of 9 monitored at $466 \mathrm{~nm}$ (solv.- $\left.\mathrm{CH}_{2} \mathrm{Cl}_{2}\right)\left(\chi^{2}\right.$ $=1.18$ ).

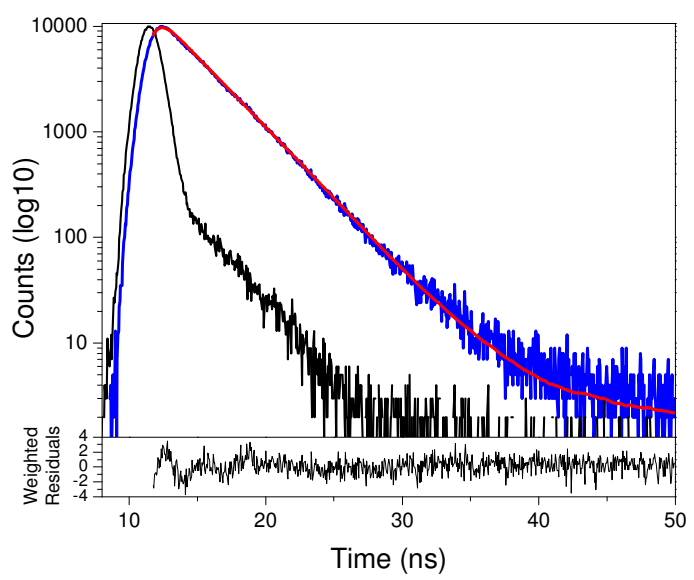

Figure S13. Decay of fluorescence of $\mathbf{1 0}$ monitored at $469 \mathrm{~nm}$ (solv.- $\left.\mathrm{CH}_{2} \mathrm{Cl}_{2}\right)\left(\chi^{2}\right.$ $=1.14)$.

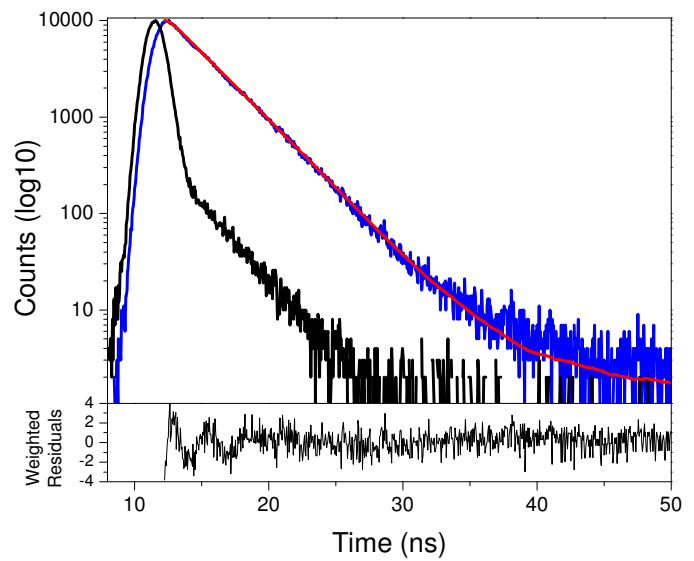

Figure S14. Decay of fluorescence of $\mathbf{1 1}$ monitored at $468 \mathrm{~nm}$ (solv.- $\left.\mathrm{CH}_{2} \mathrm{Cl}_{2}\right)\left(\chi^{2}\right.$ $=1.32$ ). 